\title{
Toll-like receptor 2 signalling and inflammation
}

\author{
F Y Liew, M Patel, D Xu
}

Ann Rheum Dis 2005;64:iv104-iv105. doi: 10.1136/ard.2005.042515

$\mathrm{T}$ oll-like receptors (TLRs) are a family of proteins that are involved in the initial phase of host defence against invading pathogens. TLRs act as primary sensors of microbial products and activate signalling pathways that lead to the induction of immune and inflammatory genes. ${ }^{1}$ TLRs belong to a broader family of proteins, which include receptors for the proinflammatory cytokines interleukin (IL)- 1 and IL-18. All members of this superfamily signal inflammation in a similar manner. This is due to the presence of a conserved protein sequence in the cytosolic domain called the Toll-IL-1 receptor (TIR) domain, which activates common signalling pathways, most notably those leading to the activation of the transcription factor NF- $\mathrm{KB}$ (nuclear factor $\kappa \mathrm{B}$ ) and stress-activated protein kinases. ${ }^{2}$ Most investigations on TLRs have focused on cells of the innate system. Furthermore, most research on the biological implications of TLRs has centred on infections. This is because the patterns recognised by TLRs are principally from pathogens. We have investigated the potential role of TLRs in an inflammatory disease, asthma.

Asthma is a chronic inflammatory condition of the airways characterised by airway hyperresponsiveness, inflammatory infiltrates in the bronchial wall containing eosinophils, and elevated serum IgE levels. T helper (Th) 2 lymphocytes are thought to play a key role in the initiation and perpetuation of this airway inflammation..$^{3-5}$ The prevalence of asthma and allergies has increased dramatically over the past 20 years in developed countries, which cannot be explained by changes in genetic predisposition. Environmental factors, especially in industrialised countries, are now thought to be responsible for this rapid increase in asthma. ${ }^{67}$

We summarise here our recent data showing that a TLR2 agonist, BLP (bacterial lipoprotein, Pam3CSK4) is highly effective in treating an established murine model of OVA specific asthma.

\section{BLP REVERSES ESTABLISHED OVA INDUCED AIRWAYS INFLAMMATION}

To investigate the therapeutic potential of BLP in reversing inflammation in allergic asthma, we employed an OVA induced murine asthma model. BALB/c mice were primed and boosted with OVA as described previously. ${ }^{8}$ Briefly, mice were immunised intraperitoneally on day 0 and 14 with $100 \mu \mathrm{g}$ OVA in an alum suspension made up to a volume of $200 \mu \mathrm{l}$. On day 14, mice were anaesthetised with $250 \mu \mathrm{l}$ of Avertin, and $100 \mu \mathrm{g}$ of OVA in $40 \mu \mathrm{l}$ of PBS was administered intranasally. Mice were again anaesthetised before being challenged intranasally on each of the days 25, 26, and 27 with $10 \mu \mathrm{g}$ OVA in $40 \mu \mathrm{l}$ of PBS. Control mice were given PBS in place of OVA in both the sensitisation and the challenge stages. Mice were sacrificed on day 29 by administration of a fatal dose of Avertin. To test the effect of TLR2 agonist, a single dose of BLP $(100 \mu \mathrm{g})$ was administered intraperitoneally on day 25,26 , or 27 , two hours after the intranasal OVA challenge. Thus, mice treated with BLP on day 27 alone would have been challenged on the previous three days with OVA.

Untreated OVA sensitised and challenged mice produced the expected airway hypersensitivity. BLP treatment showed a profound reduction in the bronchioalveolar lavage total cell count, and eosinophilia. Histological analysis demonstrated a reduction in the inflammatory infiltrates seen in the peribronchial and perivascular areas of the murine lungs treated with BLP. This decrease in airway hypersensitivity was observed on all of the days that BLP was administered. Even mice which had received all three intranasal OVA challenges showed a profound decrease in their airways inflammation, when BLP was administered two hours after their last intranasal allergen dose. This beneficial effect of BLP was sustained for at least five days after treatment. These results demonstrate that BLP could be a novel therapeutic agent for established asthma.

IMMUNOLOGICAL ANALYSIS OF THE EFFECT OF BLP To investigate the immunological mechanism involved in the BLP treatment, lymphoid cells were harvested from the BLP treated and untreated control mice and cultured with OVA in vitro. BLP did not affect the T cell proliferation against OVA in vitro. However, the lymphoid cells from BLP treated OVA sensitised/challenged mice produced significantly more interferon $\gamma($ IFN $\gamma)$ and IL-10 compared with untreated OVA sensitised/challenged mice. In contrast, BLP treatment led to a marked reduction in IL-4 and IL-5 synthesis by the lymphoid cells from OVA sensitised/challenged mice. Serum obtained from mice after BLP treatment showed a marked reduction in the concentration of OVA specific and total IgE antibody. The level of serum IL-12 was greatly increased (up to $15 \mathrm{ng} / \mathrm{ml}$ ) as early as two hours after BLP injection. Thus there appears to be a skewing of the Th 2 to Th 1 response immediately following BLP treatment.

\section{BLP ENHANCES IL- 12 AND IFN $\gamma$ SYNTHESIS IN VITRO}

To investigate the cell source and mechanism by which BLP induced IL-12 production and Th 1 cell development, we cultured bone marrow derived dendritic cells (BMDCs) with graded doses of BLP in vitro. In response to BLP, BMDCs produced significant levels of IL-12. The cells were then washed and cultured with highly purified CD4+ T cells from OVA TcR transgenic mice (DO10.11) in the presence of OVA peptide. CD4+ T cells cultured in the presence of BMDCs and BLP produced significant amounts of IFN $\gamma$ but little or no detectable IL-4. These results demonstrate that BLP is capable of inducing dendritic cells to produce IL-12, which in turn enhances the development of Th 1 cells and the production of IFN $\gamma$.

Abbreviations: BLP, bacterial lipoprotein; IFN, interferon; IL, interleukin; OVA, ovalbumin; TLR, toll-like receptor; Th, T helper; TGF, transforming growth factor 


\section{THE THERAPEUTIC EFFECT OF BLP IS IL- 12 DEPENDENT}

We then investigated the role of IL-12 in the therapeutic effect of BLP. Mice were sensitised and challenged with OVA as above and injected intraperitoneally with anti-mouse IL-12 or control rabbit IgG two hours prior to the intranasal challenge of day 27. BLP was administered two hours later. The therapeutic effect of BLP was completely abrogated by the anti-IL-12 antibody. This was clearly demonstrated by the reversal of eosinophilia, and IgE, IFN $\gamma$, IL-4, and IL-5 synthesis. Mice injected with anti-IL-12 antibody showed lung inflammatory cellular infiltration indistinguishable from that in mice sensitised to but untreated with BLP. To confirm the role of IL-12 in this model, we sensitised and challenged IL-12 ko mice with OVA and treated them with BLP as above. Whereas the wild-type control mice showed the expected beneficial effect of BLP treatment, IL-12 ko mice did not. IL-12 ko mice exhibited the same degree of eosinophilia and IL-4 synthesis and lung cellular infiltration as the untreated IL-12 ko or wild-type mice. These results therefore clearly demonstrate that the therapeutic effect of BLP in asthma is critically dependent on the preferential induction of IL- 12 .

\section{THE THERAPEUTIC EFFECT OF BLP IS IL- 10 AND TGF $\beta$ INDEPENDENT}

The enhancing effect of BLP on IL-10 production in vivo and in vitro suggests a potential role of regulatory $\mathrm{T}$ cells in the beneficial outcome of BLP treatment. IL-10 and transforming growth factor $\beta$ (TGF $\beta$ ) have been implicated as the effector of several subclasses of regulatory T cells. ${ }^{9-12}$ To investigate this possibility, mice were sensitised and challenged with OVA in the standard protocol. The animals were injected intraperitoneally with anti-mouse IL-10 receptor (R) antibody, anti-TGF $\beta$ antibody or control normal IgG, two hours before the intranasal OVA challenge on day 27. BLP therapy (day 27) was administered two hours after the last intranasal challenge. The doses of the antibodies were effective in neutralising their respective cytokines in vivo. ${ }^{12}$ Neither antiIL-10R antibody nor anti-TGF $\beta$ antibody had any effect on BAL cell counts, eosinophilia, OVA induced cell cytokine production by lymphoid cells, or inflammatory cell infiltrate in the lungs. These results indicate that the therapeutic effect of BLP in airway hypersensitivity observed is unlikely to be mediated by regulatory $\mathrm{T}$ cells.

\section{CONCLUSION AND DISCUSSION}

Our study demonstrates an impressive therapeutic role of BLP in a murine asthma model. The beneficial effect was immediate and sustained. The effect of BLP appears to be based, at least in part, on its ability to induce IL- 12 synthesis by dendritic cells. The heightened levels of IL-12 in turn enhance a specific Th 1 response and decrease Th 2 activity. The therapeutic effect is independent of IL-10 and TGF $\beta$ and, by extension, unlikely to involve regulatory $\mathrm{T}$ cells.

The role of TLR2 signalling in the induction of Th 1 and Th 2 cell development remains controversial. TLR2 activation has been reported to lead to the initiation of both Th 1 and Th 2 differentiation. ${ }^{13-15}$ It is likely that whether TLR signalling activates the Th 1 or the Th 2 pathway depends on the timing (relative to specific antigenic stimulation), dose and nature of TLR2 agonists, and the genetic background of the responding hosts. In our model, although the BLP treatment led to a mild increase in the Th 1 cytokines, the levels do not appear to be high enough to exacerbate airway hyperresponsiveness, or increase the Thl-dominant IgG2a antibody subtype. Recent reports investigating the effect of TLR2 agonists in the sensitisation phase, and the effect of a TLR $2 / 4$ agonist in the challenge phase of murine models of asthma have also shown that TLR activation could lead to a beneficial decrease in the Th 2 phenotype, with a mild non-detrimental increase in Th 1 response. ${ }^{16}{ }^{17}$

The beneficial effect of BLP and its mechanism of action appear to be akin to the TLR9 agonist, CpG oligonucleotides. TLR9 activation also led to an increase in IL-12 production from dendritic cells and an enhancement of IFN $\gamma$ synthesis by $\mathrm{T}$ cells, resulting in decreased Th 2 cell differentiation and attenuated eosinophilic airways inflammation. ${ }^{18}$ However, it has been reported that $\mathrm{CpG}$ could enhance the risk of aggravation of autoimmune disorder in immunocompetent hosts. ${ }^{19}$ Thus TLR2 agonists, such as synthetic BLP, may represent additional and alternative potential reagents for controlling allergic diseases.

\section{Authors' affiliations}

F Y Liew, M Patel, D Xu, Division of Immunology, Infection and Inflammation, University of Glasgow, Glasgow, UK

This study received financial support from the Medical Research Council, the Wellcome Trust, The Chief Scientist Office of Scotland and the European Commission.

Competing interests: none declared

Correspondence to: F Y Liew, Division of Immunology, Infection and Inflammation, University of Glasgow, Glasgow G1 1 6NT, UK; f.y.liew@ clinmed.gla.ac.uk

\section{REFERENCES}

1 Takeda K, Kaisho T, Akira S. Toll-like receptors. Annu Rev Immunol 2003;21:335-376.

2 Brint EK, Fitzgerald KA, Smith P, Coyle AJ, Gutierrez-Ramos J-C, Fallon PG, et al. Characterization of signaling pathways activated by the interleukin 1 (IL-1) receptor homologue T1/ST2. A role for jun $\mathrm{N}$-terminal kinase in IL-4 induction. J Biol Chem 2002;277:49205-11

3 Robinson D, Hamid Q, Ying S, Tsicopoulos A, Barkans J, Bentley A, et al. Predominant TH2-like bronchoalveolar T-lymphocyte population in atopic asthma. N Engl J Med 1992;326:298-304.

4 Barnes PJ, Chung KF, Page CP. Inflammatory mediators of asthma: an update. Pharmacol Rev 1998;50:515-96.

5 Holt PG, Macaubas C, Stumbles PA, Sly PD. The role of allergy in the development of asthma. Nature 1999;402:12-17.

6 Umetsu DT, Mclntire JJ, Akbari O, Macaubas C, DeKruyff RH. Asthma: an epidemic of dysregulated immunity. Nat Immunol 2002;3:715-20.

7 McKeever TM, Lewis SA, Smith C, Collins J, Heatlie H, Frischer M, et al. Early exposure to infections and antibiotics and the incidence of allergic disease: $A$ birth cohort study with the West Midlands General Practice Research Database. J Allergy Clin Immunol 2002; 109:43-50.

8 Henderson WR Jr, Lu J, Poole KM, Dietsch GN, Chi EY. Recombinant human platelet-activating factor-acetylhydrolase inhibits airway inflammation and hyperreactivity in mouse asthma model. J Immunol 2000;164:3360-7.

9 Sakaguchi S, Sakaguchi N, Asano M, Itoh M, Toda M. Immunologic selftolerance maintained by activated T cells expressing IL-2 receptor alphachains (CD25). Breakdown of a single mechanism of self-tolerance causes various autoimmune diseases. J Immunol 1995; 155:1151-64.

10 Chen Y, Kuchroo VK, Inobe J, Hafler DA, Weiner HL. Regulatory T cell clones induced by oral tolerance: suppression of autoimmune encephalomyelitis. Science 1994;265:1237-40.

11 Groux H, O'Garra A, Bigler M, Rouleau M, Antonenko S, de Vries JE, et al. A CD4+ T-cell subset inhibits antigen-specific T-cell responses and prevents colitis. Nature 1997;389:737-42.

12 Liu $H, H \cup B, X u D$, Liew FY. CD4+CD25+ regulatory T cells cure murine colitis: the role of IL-10, TGF-\{beta\}, and CTLA4. J Immunol 2003;171:5012-17.

13 Thoma-Uszynski S, Kiertscher SM, Ochoa MT, Bouis DA, Norgard MV, Miyake K, et al. Activation of toll-like receptor 2 on human dendritic cells triggers induction of IL-12, but not IL-10. J Immunol 2000;165:3804-10.

14 Sieling PA, Chung W, Duong BT, Godowski PJ, Modlin RL. Toll-like receptor 2 ligands as adjuvants for human Th1 responses. J Immunol 2003; 170:194-200.

15 Redecke V, Hacker H, Datta SK, Fermin A, Pitha PM, Broide DH, et al. Cutting edge: activation of Toll-like receptor 2 induces a Th2 immune response and promotes experimental asthma. J Immunol 2004;172:2739-43.

16 Revets H, Pynaert G, Grooten J, De Baetselier P. Lipoprotein I, a TLR2/4 ligand modulates Th2-driven allergic immune responses. J Immunol 2005; 174: 1097-103.

17 Velasco G, Campo M, Manrique OJ, Bellou A, He H, Arestides RSS, et al. Tolllike receptor 4 or 2 agonists decrease allergic inflammation. Am J Respir Cell Mol Biol 2005;32:218-24.

18 Kline JN, Kitagaki K, Businga TR, Jain VV. Treatment of established asthma in a murine model using $\mathrm{CpG}$ oligodeoxynucleotides. Am J Physiol Lung Cell Mol Physiol 2002;283:L170-L179.

19 Leadbetter EA, Rifkin IR, Hohlbaum AM, Beaudette BC, Shlomchik MJ, Marshak-Rothstein A. Chromatin-lgG complexes activate $B$ cells by dual engagement of IgM and Toll-like receptors. Nature 2002;416:603-7. 